\title{
Conduction properties of non-stoichiometric hydroxyapatite whiskers for biomedical use
}

\author{
Yumi TANAKA, ${ }^{* \dagger}$ Seiko TAKATA, ${ }^{*, * *}$ Kazuki SHIMOE, ${ }^{*, * *}$ Miho NAKAMURA, ${ }^{*}$ Akiko NAGAI, ${ }^{*}$ \\ Takeshi TOYAMA** and Kimihiro YAMASHITA* \\ *Department of Inorganic Materials, Institute of Biomaterials and Bioengineering, Tokyo Medical and Dental University, \\ 2-3-10, Kanda-Surugadai, Chiyoda-ku, Tokyo 101-0062 \\ ** Department of Materials and Applied Chemistry, Faculty of Science and Engineering, Nihon University, \\ 1-8-14, Kanda-Surugadai, Chiyoda-ku, Tokyo 101-8308
}

\begin{abstract}
Hydroxyapatite (HA) whiskers were synthesized by a hydrothermal method and ion conductive property was investigated in order to develop HA whisker electrets for biomedical utilization. Based on infrared (IR) spectroscopy and inductively coupled plasma optical emission spectrometry (ICP-OES), the obtained whiskers were assumed to be Ca deficient HA with a composition of $\mathrm{Ca}_{9.18}\left[\mathrm{HPO}_{4}\right]_{0.82}\left[\mathrm{PO}_{4}\right]_{5.18}[\mathrm{OH}]_{1.18} \cdot n \mathrm{H}_{2} \mathrm{O}$. The results of complex impedance measurements proved that the conduction properties of whiskers and powders showed almost the same temperature dependence as those of sintered $\mathrm{HA}$ above $600{ }^{\circ} \mathrm{C}$. The mechanism is understood by the migration of protons originating in $\mathrm{OH}^{-}$ions. In the temperature range below $600^{\circ} \mathrm{C}$, however, the non-linear Arrhenius relationship of conductivity ( $\sigma$ vs. 1/T) was only observed in the whiskers and powders. In particular, a drastic change in conductivity with temperature appeared in the whiskers within $250-600^{\circ} \mathrm{C}$; the conductivity increased to $5.0 \times 10^{-9} \mathrm{~S} / \mathrm{cm}$ at $500^{\circ} \mathrm{C}$, then decreased to $1.7 \times 10^{-9} \mathrm{~S} / \mathrm{cm}$ with the temperature elevated to $600^{\circ} \mathrm{C}^{\circ} \mathrm{Since}^{\mathrm{HPO}}{ }_{4}^{2-}$ ions are reportedly supposed to convert into $\mathrm{P}_{2} \mathrm{O}_{7}{ }^{4-}$ in almost the same temperature range where the drastic change in conductivity appeared, the increase in whisker conductivity up to $500^{\circ} \mathrm{C}$ is presumably the result of an increase in the number of mobile protons generated from $\mathrm{HPO}_{4}{ }^{2-}$. The subsequent decrease in conductivity seemed to be caused by a decrease in the number of protons achieved by water elimination, causing the conversion of $\mathrm{HPO}_{4}{ }^{2-}$ to $\mathrm{P}_{2} \mathrm{O}_{7}{ }^{4-}$.
\end{abstract}

(02008 The Ceramic Society of Japan. All rights reserved.

Key-words : Hydroxyapatite, Whisker, Bio ceramics, Ion conductivity, Electret, Polarization

[Received February 25, 2008; Accepted April 17, 2008]

\section{Introduction}

In order to respond to demands in the fields of medical technology, technical innovation is constantly ongoing. We consider that one of the most promising approaches to the innovation is the utilization of biomedical electrets. Since an electret has stable electric fields on its surface, some biological effects are reasonably expected. We previously reported that some types of bioceramics with relatively high ionic conductivity could be turned into electrets under a direct electric field at an elevated temperature. ${ }^{1,2)}$ The polarized biomaterials were experimentally proved as new functionalized biomaterials that can actively manipulate biological phenomena. It is also probable that a variety of biomaterials can be subjected to the poling technique because poling is a convenient post-treatment process.

Polarized hydroxyapatite (HA, $\mathrm{Ca}_{10}\left[\mathrm{PO}_{4}\right]_{6}[\mathrm{OH}]_{2}$, a wellknown artificial bone substitute) is a representative electret, in which the dipoles are formed by a slight shift of the protons in the structure. ${ }^{3), 4)}$ For dense HA ceramics, we have already reported many actual examples of manipulating biological reaction such as the enhancement of osteoconduction both in vivo and in vitro. ${ }^{5-8)}$

Concerning research on HA electrets, we are also considering morphology and stoichiometry. Since HA demonstrates different chemical and mechanical properties depending on the crystal faces in the hexagonal lattice, ${ }^{9)}$ the HA whiskers with anisotropic

\footnotetext{
Corresponding author: Y. Tanaka; E-mail: tanaka.bcr@tmd.ac.jp
}

growth orientation usually show, for example, excellent selectivity in the absorption of biological materials and good reinforcement efficiency by mixing with the other biomaterials. ${ }^{10)}$ Combining the morphology-based functions with electromagnetic functionalization via the poling treatment is leading researchers to the expectation of expanded applications of HA whiskers. For the control of electromagnetic power on the HA whiskers, however, very little study of the details of the ion conductive properties of the whiskers has been done. This paper deals with the ion conductive properties of HA whiskers from the perspective of comparing HA powders and sintered HA with isotropic growth orientations.

\section{Experimental procedure}

\subsection{Synthesis of HA whiskers and powders}

HA whiskers were synthesized via amorphous calcium phosphate (ACP) because large, pure crystals could be obtained when ACP was used as a precursor. $^{11)}$ The procedure is briefly described below. ACP was precipitated by pouring $1.0 \mathrm{~mol} / \mathrm{l}$ $\left[\mathrm{NH}_{4}\right]_{2} \mathrm{HPO}_{4}$ aqueous solution into an equal volume of $0.17 \mathrm{~mol} / \mathrm{l}$ $\mathrm{Ca}\left[\mathrm{NO}_{3}\right]_{2}$ aqueous solution. The $\mathrm{pH}$ of the $\left[\mathrm{NH}_{4}\right]_{2} \mathrm{HPO}_{4}$ solution was adjusted to 10.5 by ammonia in advance. After washing and drying, $0.8 \mathrm{~g}$ of the ACP powders was ultrasonically dispersed into $24 \mathrm{ml}$ of $1.0 \mathrm{~mol} / \mathrm{l} \mathrm{CH}_{3} \mathrm{COOH}$ aqueous solution and then 12 $\mathrm{ml}$ of diluted water was added to it. The prepared ACP suspension was converted into a suspension of HA whiskers under hydrothermal conditions at $210^{\circ} \mathrm{C}$ for $3 \mathrm{~h}$ in a sealed vessel. The ionic ratio of the obtained HA whiskers was analyzed by induc- 
tively coupled plasma optical emission spectrometry (ICP-OES). Alternatively, HA powders were synthesized by the wet method as follows. $\mathrm{CaO}$ powders were converted into a $\mathrm{Ca}[\mathrm{OH}]_{2}$ suspension (7.0 mass \%) by pouring into decarbonated water. Until the molar ratio of $\mathrm{Ca} / \mathrm{P}$ reached $1.67, \mathrm{H}_{3} \mathrm{PO}_{4}$ aqueous solution (28 mass\%) was dropped into the suspension under stirring. After stirring for another several tens of hours, the precipitate was filtered, washed, and dried, resulting in HA powders. The morphology of the synthesized HA whiskers and powders were observed by using a scanning electron microscope (SEM). The crystal structure was identified by $2 \theta / \theta$ X-ray diffraction measurement (XRD) using $\mathrm{Cu} \mathrm{K} \alpha$ radiation. The conditions of ionic binding were estimated by the results of infrared (IR) spectroscopy. Thermogravimetric analysis was also carried out in order to investigate the thermal water elimination from HA whiskers and powders.

\subsection{Ion conductivity measurement}

For ion conductivity measurements, HA whiskers and powders were isostatically pressed into compacts $(\varphi 13 \mathrm{~mm}$, thickness 1.0 $\mathrm{mm}$ ) under a pressure of $150 \mathrm{MPa}$. For comparison, a dense HA pellet was also prepared by sintering the powder compact at $1250^{\circ} \mathrm{C}$ for $2 \mathrm{~h}$. During the sintering, water vapor was introduced into the furnace in order to prevent the release of $\mathrm{OH}^{-}$ions from the HA.

Ion conductivity was estimated by the results of complex impedance measurements of the samples with Pt electrodes. The measurements were carried out in the air in the frequency range of $100 \mathrm{~Hz}-10 \mathrm{MHz}$ with an applied AC voltage of $0.1 \mathrm{~V}$. The temperature range was from room temperature to $850^{\circ} \mathrm{C}$ at increments of $5^{\circ} \mathrm{C} / \mathrm{min}$ while $10 \mathrm{~min}$ intervals were provided at each measured temperature. The morphology and structural changes with impedance measurements were estimated by SEM, XRD, and IR measurements.

\section{Results and discussion}

\subsection{Characterizations of as-deposited HA whiskers and powders}

Figure 1 shows SEM photographs of as-deposited HA crystals synthesized by the hydrothermal treatment of ACP (Fig. 1(a)) and by the wet method (Fig. 1(b)). It is clear that there is large difference in morphology between them: the former consists of large whiskers with an anisotropic aspect of $10-20 \mu \mathrm{m}$ in length and $1.0-1.5 \mu \mathrm{m}$ in width, while the latter consists of aggregates of spherical particles with a diameter of $0.2-0.3 \mu \mathrm{m}$. In the XRD patterns of as-deposited HA whiskers and powders, all peaks in both are identified as diffractions of HA and there are no obvious differences in the peak positions (Fig. 2). The lattice constant was calculated to be $a=b=9.430$ (6), $c=6.884$ (4) for the whiskers and $a=b=9.426$ (4), $c=6.885$ (2) for the powders, showing that the crystal structure of the whiskers was consistent with that of the powders. However, the peak shapes of the whiskers seemed to be broader than were those of the powders, except for a peak that originated in (002). It was also found that the relative intensity of some peaks such as (002) and (300) was different between the whiskers and powders. The coherent region for XRD diffraction along the $c$ - and $a$-axes was estimated by full width half maximum of the peak of (002) and (300) using Scherrer relation; the values obtained were $0.11 \mu \mathrm{m}$ and $0.04 \mu \mathrm{m}$ for the whiskers and $0.11 \mu \mathrm{m}$ and $0.09 \mu \mathrm{m}$ for the powders. Based on the results, the coherent region along the $c$-axis in the whiskers was about 3 times as large as the region for the $a$-axis. The smaller coherent region and the aspect ratio of whiskers in comparison with those estimated by the SEM observation indicate the aggregation of several numbers of crystalline in one whisker. Figures 3A(a) and (b) are IR patterns of the whiskers and powders. In both patterns, the characteristic absorbance that originated in the vibrations of the $\mathrm{PO}_{4}{ }^{3-}$ and $\mathrm{OH}^{-}$ions in the $\mathrm{HA}$ structure was observed. It is generally known that the preparation of pure, large $\mathrm{HA}$ whiskers without $\mathrm{CO}_{3}{ }^{2-}$ is difficult. ${ }^{12), 13)}$ However, judging from the lack of typical absorption by $\mathrm{CO}_{3}{ }^{2-}$ (Fig. 3A(a)), the whiskers in this study were shown to not include any $\mathrm{CO}_{3}{ }^{2-}$. The peaks that originated in the stretching mode of the $\mathrm{P}-\mathrm{O}$ bonds and the bending mode of the $\mathrm{O}-\mathrm{P}-\mathrm{O}$ bonds are marked with short solid lines (sharp peaks at about 962 $\mathrm{cm}^{-1}$ and broad peaks around $1030-1090 \mathrm{~cm}^{-1}$ ) and with short dotted lines (peaks at about 470, 560, and $600 \mathrm{~cm}^{-1}$ ) in the Figs., respectively. Absorbance by the $\mathrm{OH}^{-}$ions is marked with solid cones; the peaks at about $630 \mathrm{~cm}^{-1}$ and $3570 \mathrm{~cm}^{-1}$ were attributed to the librational and stretching modes. The good agreement in the positions of the above-described peaks with those reported by Koutsopoulos $^{14)}$ suggests that both of the whiskers and powders synthesized in this study have basically the same ionic binding energy in the $\mathrm{PO}_{4}{ }^{3-}$ ion and $\mathrm{OH}^{-}$ion with that of stoichiometric HA. However IR absorption by the $\mathrm{OH}^{-}$ions in the whiskers was lower than that in the powders. The relative peak intensity of $\mathrm{OH}^{-}$libration $\left(630 \mathrm{~cm}^{-1}\right)$ against $\mathrm{O}-\mathrm{P}-\mathrm{O}$ bending $(470,560$, and $600 \mathrm{~cm}^{-1}$ ) was $28.1 \%$ for the whiskers and $41.4 \%$ for the powders. This fact probably means that the $\mathrm{OH}^{-}$content in the whiskers is about $68 \%$ when the content in the powders is assumed to be $100 \%$. Furthermore, in the case of whiskers, an additional peak and shoulder appeared at around $870 \mathrm{~cm}^{-1}$ (see magnified patterns in Fig. 3B) and $1145 \mathrm{~cm}^{-1}$, indicating the presence of $\mathrm{HPO}_{4}{ }^{2-}$ ions in HA. It was reported that absorbance peaks at $962 \mathrm{~cm}^{-1}$ and around $1020-1100 \mathrm{~cm}^{-1}$ also appeared in the IR pattern if $\mathrm{HA}$ includes $\mathrm{HPO}_{4}{ }^{2-}{ }^{14)}$ A little difference in the shapes around the peaks of $\mathrm{O}-\mathrm{P}-\mathrm{O}$ bending between the whiskers and powders is also thought to arise from the presence of

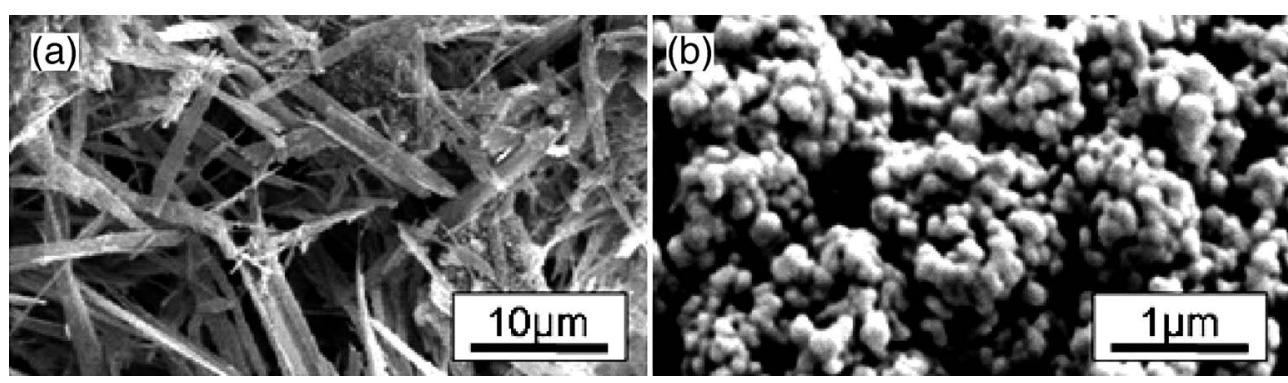

Fig. 1. SEM photographs of as-deposited HA crystalline prepared by (a) hydrothermal method via ACP and (b) wet method. 


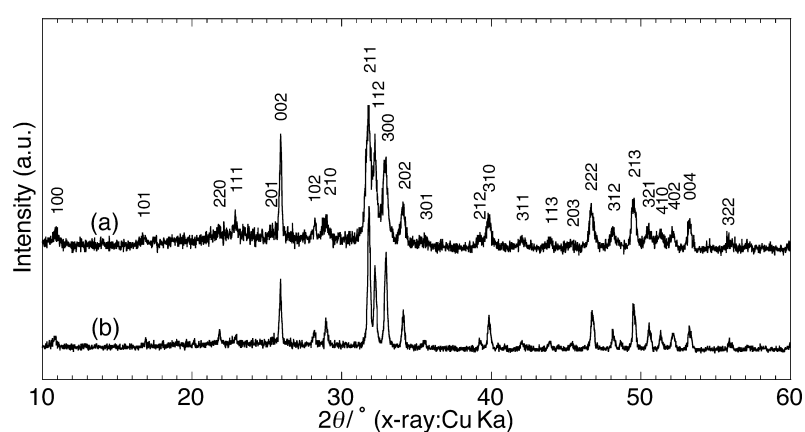

Fig. 2. XRD patterns of (a) as-deposited HA whiskers and (b) asdeposited HA powders.
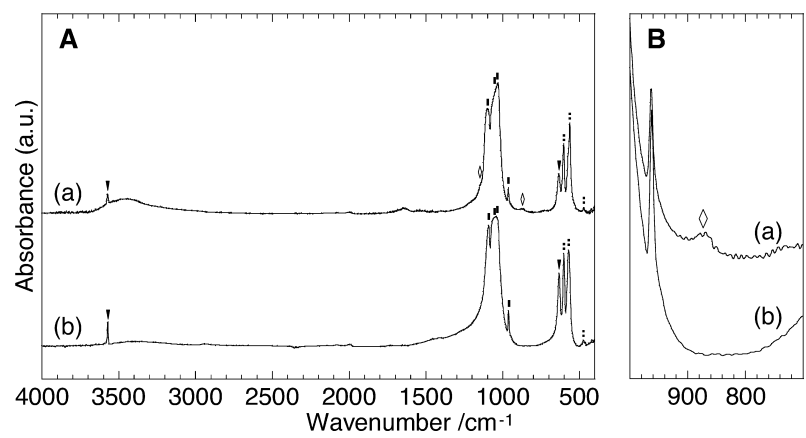

Fig. 3. IR spectra of (a) as-deposited HA whiskers and (b) as-deposited HA powders; A) the patterns in wide wavenumber range of $400-4000 \mathrm{~cm}^{-1}$ and $\mathrm{B}$ ) the magnified patterns around $700-1000 \mathrm{~cm}^{-1}$. The short solid lines and short dotted lines denote the peaks of $\mathrm{PO}_{4}{ }^{3-}$ (stretching and bending modes) and the solid triangles and open rhombus denote the peaks of $\mathrm{OH}^{-}$ and $\mathrm{HPO}_{4}{ }^{2-}$, respectively.

$\mathrm{HPO}_{4}{ }^{2-}$ ions in the whiskers. Actually, as a result of ICP-OES measurement, $\mathrm{Ca} / \mathrm{P}$ molar ratios were calculated to be 1.53 for the whiskers and 1.63 for the powders. Considering these results, the ionic composition of the whiskers was calculated to be $\mathrm{Ca}_{9.18}\left[\mathrm{HPO}_{4}\right]_{0.82}\left[\mathrm{PO}_{4}\right]_{5.18}[\mathrm{OH}]_{1.18} \cdot n \mathrm{H}_{2} \mathrm{O}$ by assuming the following general formula for calcium-deficient $\mathrm{HA}:{ }^{15)-17)}$

$$
\mathrm{Ca}_{10-z}\left[\mathrm{HPO}_{4}\right]_{z}\left[\mathrm{PO}_{4}\right]_{6-z}[\mathrm{OH}]_{2-z} \cdot n \mathrm{H}_{2} \mathrm{O}(z=0-1) \text {. }
$$

Although no IR absorption peaks of $\mathrm{HPO}_{4}{ }^{2-}$ were detected, the powders also seemed to include a small calcium deficiency. The composition was calculated to be $\mathrm{Ca}_{9.78}\left[\mathrm{HPO}_{4}\right]_{0.22}\left[\mathrm{PO}_{4}\right]_{5.78}$ $[\mathrm{OH}]_{1.78} \cdot n \mathrm{H}_{2} \mathrm{O}$. The $\mathrm{OH}^{-}$content in the whiskers (1.18) corresponds to about $66 \%$ of the content in the powders (1.78), and is in good agreement with the results of the IR measurements.

The thermogravimetric behavior of the HA whiskers and powders is shown in Fig. 4A, where $x$ denotes molar water elimination per molar composition of $\mathrm{Ca}_{10-z}\left[\mathrm{HPO}_{4}\right]_{z}\left[\mathrm{PO}_{4}\right]_{6-z}[\mathrm{OH}]_{2-z}(z=$ 0.82 for whiskers and 0.22 for powders). It can be found that the total water eliminated from the whiskers was significantly greater than that from the powders. Based on the temperature differentiation of the thermogravimetric behavior, water elimination from the whiskers seems to progress through mostly four stages that occur in the temperature ranges of $25-250^{\circ} \mathrm{C}$ (peak maximum: $80^{\circ} \mathrm{C}$ ), $250-400^{\circ} \mathrm{C}$ (peak maximum: $340^{\circ} \mathrm{C}$ ), $400-600^{\circ} \mathrm{C}$ (peak maximum: $550^{\circ} \mathrm{C}$ ), and $700-900^{\circ} \mathrm{C}$ (peak maximum: $790^{\circ} \mathrm{C}$ ) (Fig. 4B). According to previous reports, ${ }^{18)-20)}$ the first stage is the elimination of adsorbed water from the surface and fine pores. The significantly larger mass loss from the whiskers
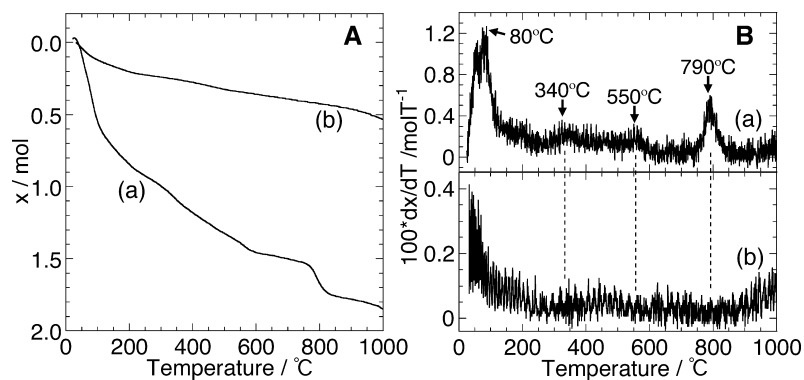

Fig. 4. Thermogravimetric behavior of water in (a) as-deposited HA whiskers and (b) as-deposited HA powders; A) accumulated amount of water eliminated with temperature and B) temperature differentiation of water elimination. The value $x$ denotes molar water elimination per molar composition of whiskers and powders.

than from the powders at this stage is consistent with the results of IR measurement, in which the greater IR absorption by the adsorbed water (around 3000-3800 $\mathrm{cm}^{-1}$ ) was detected in the whiskers compared with the powders. In contrast, it is known that calcium deficient HA has lower thermal stability than does stoichiometric HA and it decomposes into stoichiometric HA and $\beta$-tricalcium phosphate (TCP) via the following reaction: ${ }^{17), 21)}$

$$
\begin{aligned}
& \mathrm{Ca}_{10-z}\left[\mathrm{HPO}_{4}\right]_{z}\left[\mathrm{PO}_{4}\right]_{6-z}[\mathrm{OH}]_{2-z} \rightarrow \\
& (1-z) \mathrm{Ca}_{10}\left[\mathrm{PO}_{4}\right]_{6}[\mathrm{OH}]_{2}+3 z \mathrm{Ca}_{3}\left[\mathrm{PO}_{4}\right]_{2}+z \mathrm{H}_{2} \mathrm{O} .
\end{aligned}
$$

In this reaction, the formation of $\beta$-TCP occurs around 700$900^{\circ} \mathrm{C}$ after $\mathrm{HPO}_{4}{ }^{2-}$ is slowly converted into $\mathrm{P}_{2} \mathrm{O}_{7}{ }^{4-}$ in the temperature range of $300-680^{\circ} \mathrm{C}$ accompanied by water elimination $\left(2 \mathrm{HPO}_{4}{ }^{2-} \rightarrow \mathrm{P}_{2} \mathrm{O}_{7}{ }^{4-}+\mathrm{H}_{2} \mathrm{O}\right)$. By recognizing that the whiskers consisted of calcium-deficient HA, the loss of mass in the second and third stages is assumed to occur due to the conversion of $\mathrm{HPO}_{4}{ }^{2-}$ into $\mathrm{P}_{2} \mathrm{O}_{7}{ }^{4-}$. Decomposition from the intermediate compound including $\mathrm{P}_{2} \mathrm{O}_{7}{ }^{4-}$ to $\mathrm{HA}$ and $\beta$-TCP takes place during the final stage:

$$
\begin{aligned}
& \mathrm{Ca}_{9.18}\left[\mathrm{HPO}_{4}\right]_{0.82}\left[\mathrm{PO}_{4}\right]_{5.18}[\mathrm{OH}]_{1.18} \\
& \rightarrow \mathrm{Ca} 9.18\left[\mathrm{P}_{2} \mathrm{O}_{7}\right]_{0.41}\left[\mathrm{PO}_{4}\right]_{5.18}[\mathrm{OH}]_{1.18}+0.41 \mathrm{H}_{2} \mathrm{O} \\
& \qquad \text { (second and third stages) } \\
& \rightarrow 0.18 \mathrm{Ca}_{10}\left[\mathrm{PO}_{4}\right]_{6}[\mathrm{OH}]_{2}+2.46 \mathrm{Ca}_{3}\left[\mathrm{PO}_{4}\right]_{2}+0.41 \mathrm{H}_{2} \mathrm{O}
\end{aligned}
$$

(final stage).

In the case of the powders, a very small loss of mass was observed in the temperature range of $300-680^{\circ} \mathrm{C}$ and no loss of mass was detected around $700-900^{\circ} \mathrm{C}$. The observation indicates that the thermal stability of powders with small deficiencies is great enough to prevent thermal decomposition into $\beta$-TCP at temperatures below $1000^{\circ} \mathrm{C}$.

\subsection{Ion conduction property of HA whiskers}

In Figs. 5A, B, C, and D, the typical impedance responses of the whisker compact (denoted by solid circles) and powder compact (denoted by open circles) at $250,500,600$, and $850^{\circ} \mathrm{C}$ are shown as complex impedance plots with those of the sintered HA (denoted by open rhombi) as the reference. All plots consisted of a single semicircle described by a simple equivalent circuit of one capacitance and one resistance in parallel. Because the resistances of the crystalline grains and the grain boundaries were not separated, the conductivity was calculated by the total resistance of the grains and the grain boundaries. To eliminate 

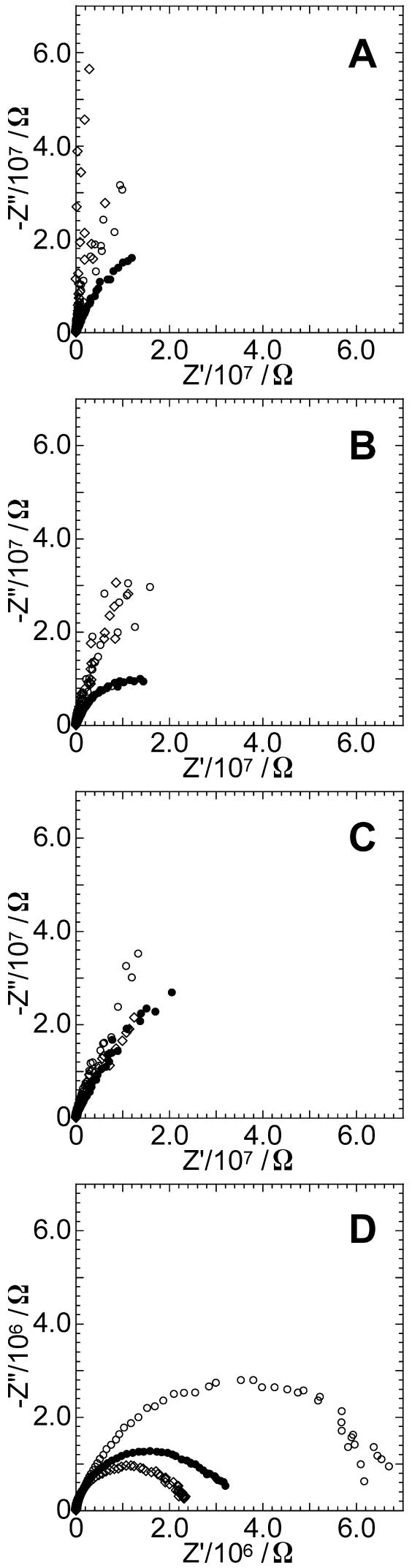

Fig. 5. Typical complex impedance plots of compacted HA whiskers, compacted HA powders, and sintered $\mathrm{HA}$ at A) $250^{\circ} \mathrm{C}$, B) $500^{\circ} \mathrm{C}$, C) $600^{\circ} \mathrm{C}$, and D) $850^{\circ} \mathrm{C}$. Solid and open circles denote the plots of compacted HA whiskers and powders, respectively, and open rhombus denote the plot of sintered HA. the effects of void volume, the values were corrected by relative densities (whisker compact: 62\% against $\mathrm{Ca}_{9.18}\left[\mathrm{HPO}_{4}\right]_{0.82}$ $\left[\mathrm{PO}_{4}\right]_{5.18}[\mathrm{OH}]_{1.18}$, powder compact: $57 \%$ and sintered pellets: 96\% against HA). The obtained conductivity is shown as the Arrhenius relationship (Fig. 6), showing that the three samples exhibited almost the same temperature dependence in the higher temperature range above $600^{\circ} \mathrm{C}$. The linear increase of conductivity with the inverse of temperature is characteristic of the preferential ion conduction mechanism. As briefly described in the introduction section, conductivity in sintered HA has been reported to be the result of the migration of protons supplied by $\mathrm{OH}^{-}$ions in the HA structure. The activation energy of the proton migration through $\mathrm{OH}^{-}$ions in $\mathrm{HA}$ is a relatively higher value of around $1 \mathrm{eV},{ }^{1)}$ which shows good agreement not only with the activation energy of sintered HA in this study $(1.03 \mathrm{eV})$ but also the values of the whisker compact $(1.03 \mathrm{eV})$ and powder compact $(1.09 \mathrm{eV})$ for temperatures above $600^{\circ} \mathrm{C}$. This suggests that the conductivity of the whiskers and powders is also attributed to the protons in the $\mathrm{OH}^{-}$ions in this temperature region. In contrast in the temperature range below $600^{\circ} \mathrm{C}$, it is interesting to note that the non-linear temperature dependence of conductivity could be observed in the whiskers and powders, while the conductivity of the sintered HA was difficult to calculate because of the detection limit of the impedance. In particular, the whiskers showed the unique behavior that the conductivity once increased to around $5.0 \times 10^{-9} \mathrm{~S} / \mathrm{cm}$ and then decreased with temperature from 500 to $600^{\circ} \mathrm{C}$. The conductivity of whiskers at $500^{\circ} \mathrm{C}$ was about one order of magnitude greater than powders at the same temperature and corresponded to the value of the whiskers at $700^{\circ} \mathrm{C}$. It was assumed that the non-linear relationship probably came from the multiple ion migration mechanism.

\subsection{Thermal change of HA whiskers after imped- ance measurements}

Figure 7 shows SEM photographs of the surface of the compacted whiskers (a) and powders (b) before (1 in Figs. 7(a) and (b)) and after (2 in Figs. 7(a) and (b)) the impedance measurements. Because the non-linearity in the Arrhenius plot was observed below $600^{\circ} \mathrm{C}$, the observation was also conducted for the surface after the measurement at $600^{\circ} \mathrm{C}$ (3 in Figs. 7(a) and (b)). As for the whisker compact, whisker shaped crystals (2-4 $\mu \mathrm{m}$ long and $0.1-0.3 \mu \mathrm{m}$ wide) could be observed in both photographs 1 and 2 with no change in morphology after the measurement at $600^{\circ} \mathrm{C}$. There seemed to be no relationship between conductivity and morphology. The smaller size of the whiskers than the as-deposited ones (see Fig. 1(a)) was probably caused by partial collapse of the grain under the high pressure while the compact was formed. In contrast, it was found that the morphology in Fig. 7(a)-3 was slightly different compared to Figs. 7(a)1 and 2, suggesting that the morphology change from the anisotropic shape to the isotropic shape occurred during the temperature elevation from $600^{\circ} \mathrm{C}$ to $850^{\circ} \mathrm{C}$. The Arrhenius plot of the whiskers, however, showed the linear relationship in this temperature region as described in the paragraph on the ion conductive properties. Considering this, proton conduction above $600^{\circ} \mathrm{C}$ probably occurred over a short distance within the crystal, which was little affected by changes in the sizes of the secondary particles. In the case of the powder compact, the morphology seemed not to change during the measurement from room temperature to $850^{\circ} \mathrm{C}$.

The change of crystal structure in the samples after the impedance measurement was estimated by the XRD patterns of the surface of the whisker compact (Fig. 8(a)) and powder compact 


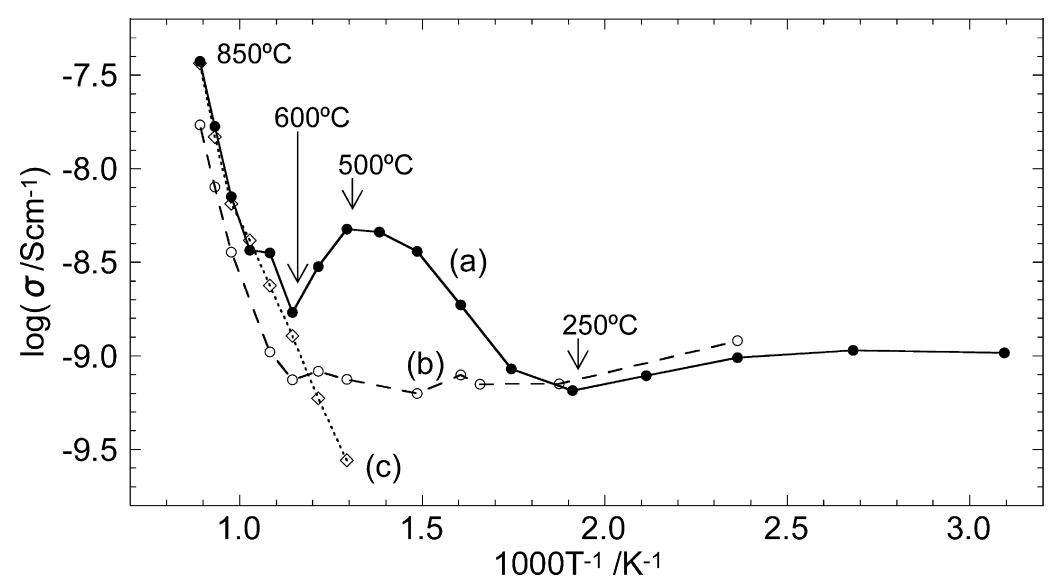

Fig. 6. Arrhenius plots of ionic conduction in (a) compacted HA whiskers, (b) compacted HA powders, and (c) sintered HA.
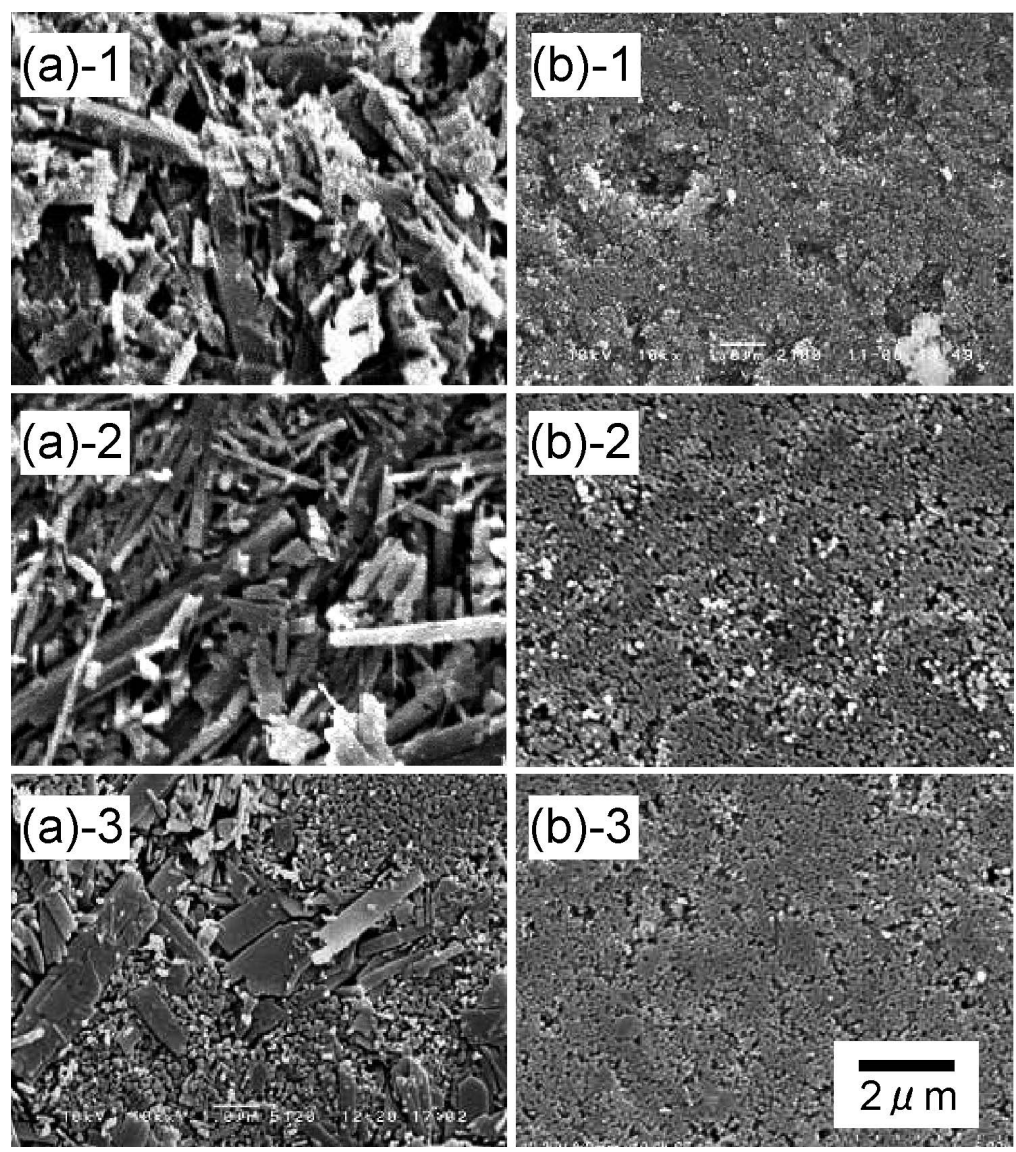

Fig. 7. SEM photographs of the surface of (a) compacted HA whiskers, (b) compacted HA powders, and (c) sintered HA. Photograph 1 represents the surface before impedance measurement and photographs 2 and 3 represent the surface after impedance measurement at $600^{\circ} \mathrm{C}$ and $850^{\circ} \mathrm{C}$, respectively.

(Fig. 8(b)). 1, 2, and 3 correspond to the patterns before the impedance measurement, after the measurement at $600^{\circ} \mathrm{C}$, and at $850^{\circ} \mathrm{C}$, respectively. For reference, the patterns of the as-deposited samples (pattern 0) are shown in Fig. 8. Compared to Fig. 8(a)-0, the intensity of (002) diffraction in Figs. 8(a)-1, 2, and 3 drastically decreased instead of the increase in diffraction from (300). This was surely caused by the effect of preferred orientation of the whiskers on the surface of the compact. Similarly, the difference in relative intensity observed among Figs. 8(a)-1, 2, and 3 seems not to be the result of the structural change during the impedance measurement but to the difference in the condition of the preferred orientation from lot to lot introduced during formation of the compact. There were no obvious changes in the diffraction positions $(2 \theta)$ that originated in HA among all whisker samples, whereas the additional peaks from $\beta$-TCP (denoted by solid cones) appeared only in Fig. 8(a)-3. Based on these results, it was assumed that the unique conductivity profile of whiskers below $600^{\circ} \mathrm{C}$ was not the result of a change of the 


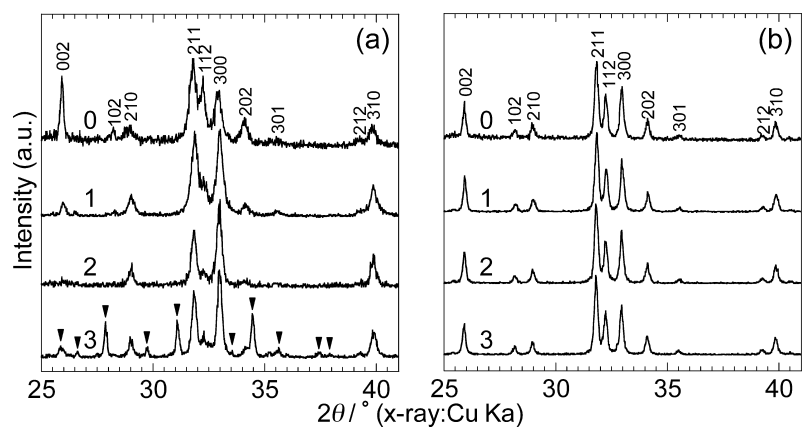

Fig. 8. XRD patterns of (a) HA whiskers and (b) HA powders. Pattern 0 represents the diffraction from as-deposited whiskers and powders, pattern 1 represents the diffraction from the surface of compacted samples before impedance measurement, and patterns 2 and 3 represent the surface of compacted samples after impedance measurement at $600^{\circ} \mathrm{C}$ and $850^{\circ} \mathrm{C}$, respectively.

crystal structure, and the ion conduction mechanism above $600^{\circ} \mathrm{C}$ was free from the influence of $\beta$-TCP generation. As for the powder compact, there seemed to show no changes in peak position during the impedance measurement from room temperature to $850^{\circ} \mathrm{C}$. The result also indicates that the presumed multiple mechanisms in conductivity below $600^{\circ} \mathrm{C}$ were not brought about by structural change.

Figures 9(a) and (b) are the IR patterns of the whiskers and powders before the impedance measurement (1), after the measurement at $600^{\circ} \mathrm{C} \mathrm{(2),} \mathrm{and} \mathrm{after} \mathrm{the} \mathrm{measurement} \mathrm{at} 850^{\circ} \mathrm{C}$ (3). During the temperature elevation from $600^{\circ} \mathrm{C}$ to $850^{\circ} \mathrm{C}$, a significant change in the pattern attributable to the generation of $\beta$ TCP was observed in the whiskers. However, this change was considered as having no influence on proton migration in the HA crystal as judged by the linear relationship in the Arrhenius plot. In contrast, in the temperature range below $600^{\circ} \mathrm{C}$, it was found that absorbance around 1030-1090 $\mathrm{cm}^{-1}$ (stretching mode of $\mathrm{P}-$ $\mathrm{O}$ bonds in $\mathrm{PO}_{4}{ }^{3-}$ ion) sharpened slightly after the measurement

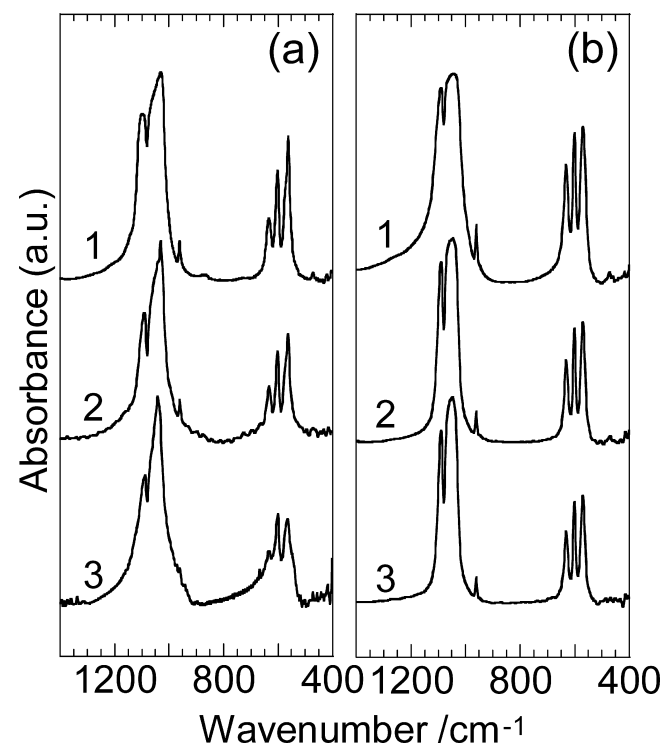

Fig. 9. IR spectra of (a) HA whiskers and (b) HA powders. Spectrum 1 represents IR absorption by samples before impedance measurement and spectra 2 and 3 represent IR absorption by samples after impedance measurement at $600^{\circ} \mathrm{C}$ and $850^{\circ} \mathrm{C}$, respectively. at $600^{\circ} \mathrm{C}$ in both the whisker and powder patterns. In addition, as for the whiskers, the absorption at $870 \mathrm{~cm}^{-1}$ that originated in $\mathrm{HPO}_{4}{ }^{2-}$ disappeared after the measurement at $600^{\circ} \mathrm{C}$. These results support the interpretation of mass loss in the TG curves (Fig. 4) that $\mathrm{HPO}_{4}{ }^{2-}$ in the calcium-deficient $\mathrm{HA}$ converted into $\mathrm{P}_{2} \mathrm{O}_{7}{ }^{4-}$ at the second and third stages $\left(250-600^{\circ} \mathrm{C}\right)$. The drastic change in whisker conductivity was observed in almost the same temperature range from 250 to $600^{\circ} \mathrm{C}$, indicating that the $\mathrm{HPO}_{4}{ }^{2-}$ had a close correlation to the ion conduction in the whiskers. By plotting the TG curves on the Arrhenius plots of conductivity (Fig. 10), it was found that the conductivity changes are closely related to water elimination. In the temperature range low enough to allow the adsorbed water to exist on the surface, proton conduction is supposed to occur via the adsorbed water. This kind of surface conduction usually decreases with an increase in the temperature because the conduction path decreases with the elimination of adsorbed water, whereas the probability of generation of movable carriers increases with temperature. The apparent non-linear relationship between $\sigma$ against $1 / T$ below $250^{\circ} \mathrm{C}$ was probably caused by the binary interaction of the decreasing and increasing conduction through adsorbed water with temperature elevation. In contrast, based on the results of TG and IR measurements, the temperature range of $250-400^{\circ} \mathrm{C}$ corresponds to the second stage where the proton in $\mathrm{HPO}_{4}{ }^{2-}$ has high mobility for conversion into $\mathrm{P}_{2} \mathrm{O}_{7}{ }^{4-}$. The amount of water eliminated during the heating from $250^{\circ} \mathrm{C}$ to $400^{\circ} \mathrm{C}$ was estimated to be about $x=$ 0.26 for the whiskers (Fig. 4A(a)). Since a value of $x=0.41$ is obtained for the complete conversion from $\mathrm{HPO}_{4}{ }^{2-}$ to $\mathrm{P}_{2} \mathrm{O}_{7}{ }_{7}^{4-}$, it was considered that the protons were retained within the whiskers up to at least $400^{\circ} \mathrm{C}$. By taking into account the existence of two main stages of the second and third stages during the conversion, suggestion of the following two-step reactions was possible:
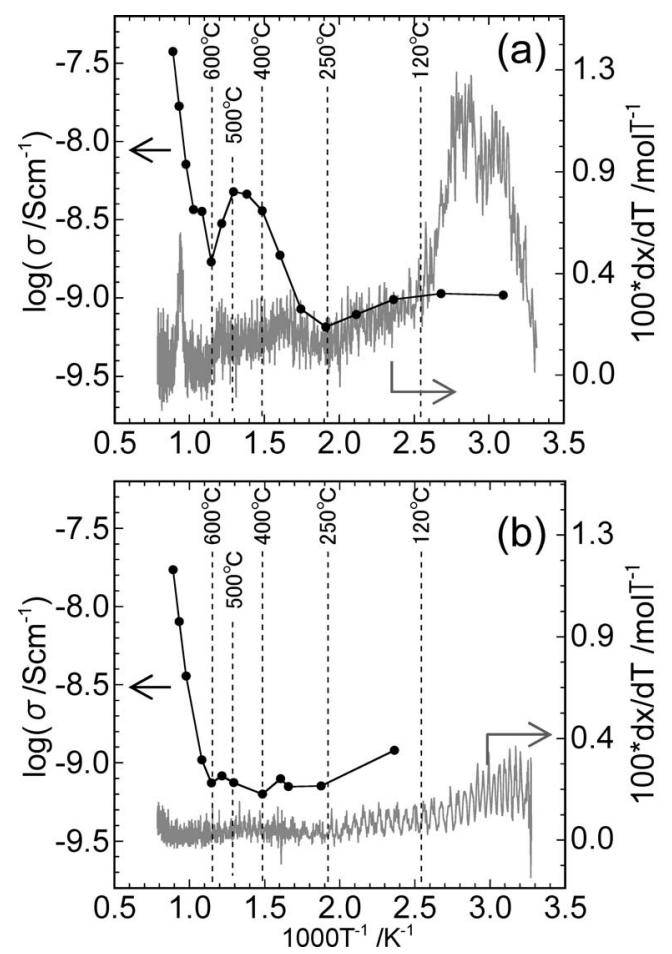

Fig. 10. Arrhenius plots of ionic conduction in (a) compacted HA whiskers and (b) compacted HA powders with the plots of temperature differentiation of water elimination from each sample against inverse temperature. 


$$
\begin{aligned}
& \mathrm{Ca}_{9.18}\left[\mathrm{HPO}_{4}\right]_{0.82}\left[\mathrm{PO}_{4}\right]_{5.18}[\mathrm{OH}]_{1.18} \\
& \rightarrow \mathrm{Ca}_{9.18}\left[\mathrm{P}_{2} \mathrm{O}_{7}\right]_{0.41}\left[\mathrm{PO}_{4}\right]_{5.18}\left[\mathrm{OH}^{-}\right]_{1.18+\delta}\left[\mathrm{H}^{+}\right]_{\delta}+(0.41-\delta) \mathrm{H}_{2} \mathrm{O}
\end{aligned}
$$

(second stage),

and

$$
\begin{aligned}
& \mathrm{Ca}_{9.18}\left[\mathrm{P}_{2} \mathrm{O}_{7}\right]_{0.41}\left[\mathrm{PO}_{4}\right]_{5.18}\left[\mathrm{OH}^{-}\right]_{1.18+\delta}\left[\mathrm{H}^{+}\right]_{\delta} \\
& \rightarrow \mathrm{Ca}_{9.18}\left[\mathrm{P}_{2} \mathrm{O}_{7}\right]_{0.41}\left[\mathrm{PO}_{4}\right]_{5.18}[\mathrm{OH}]_{1.18}+\delta \mathrm{H}_{2} \mathrm{O}
\end{aligned}
$$

(third stage).

The high conductivity at the second stage is presently attributed to the proton migration $\left(\delta \mathrm{H}^{+}\right)$in the HA lattice. The subsequent decrease of conductivity at the third stage might result from the decrease in the number of protons generated with the water elimination. In the case of the powders, the same mechanism was basically supposed to cause the non-linear behavior in conductivity below $600^{\circ} \mathrm{C}$, while the degree of change was much smaller than that in the whiskers.

\section{Conclusion}

HA whiskers synthesized via ACP were proved to be Ca-deficient $\mathrm{HA}$ with a $\mathrm{Ca} / \mathrm{P}$ molar ratio of 1.53 . The $\mathrm{HPO}_{4}{ }^{2-}$ in the Cadeficient whiskers was responsible for the high ionic conductivity in the temperature range of $250-600^{\circ} \mathrm{C}$. Since the practical temperature for the poling of $\mathrm{HA}$ is $200-500^{\circ} \mathrm{C}$ based on our previous studies, the high ionic conduction below $600^{\circ} \mathrm{C}$ in Ca-deficient whiskers can be used for controlling the poling conditions. Furthermore, it seems to be possible to attain higher conductivity by controlling the concentration of $\mathrm{HPO}_{4}{ }^{2-}$. Because of the excellent selectivity in the adsorption of biological materials and electromagnetic functionalization, HA whiskers are expected to play an important role in the expansion of biomedical applications. The polarization properties of a series of Ca-deficient HA whiskers and the poling effect of HA whisker electrets on biological materials are currently being studied.

Acknowledgments This work was partly supported by a Grantin-Aid from the Japan Society for the Promotion of Science (\#19300169). Some of the authors (Y. T., M. N., and A. N.) would also like to express their thanks to "The Kazuchika Okura Memorial
Foundation" for a grant for this research.

\section{References}

1) K. Yamashita, K. Kitagaki and T. Umegaki, J. Am. Ceram. Soc., 78[5], 1191-1197 (1995).

2) A. Obata, S. Nakamura and K. Yamashita, Biomaterials, 25[21], 5163-5169 (2004).

3) M. Ueshima, S. Nakamura and K. Yamashita, Adv. Mater., 14[8], 591-595 (2002).

4) S. Nakamura, H. Takeda and K. Yamashita, J. Appl. Phys., 89[10], 5386-5392 (2001).

5) M. Nakamura, K. Niwa, S. Nakamura, Y. Sekijima and K. Yamashita, J. Biomed. Mater. Res. B, 82B[1], 29-36 (2007).

6) S. Itoh, S. Nakamura, M. Nakamura, K. Shinomiya and K. Yamashita, Biomaterials, 27[32], 5572-5579 (2006).

7) S. Nakamura, T. Kobayashi and K. Yamashita, J. Biomed. Mater. Res. A, 61[4], 593-599 (2002).

8) T. Kobayashi, S. Nakamura and K. Yamashita, J. Biomed. Mater. Res. A, 57[4], 477-484 (2001).

9) T. Kawasaki, J. Chromatogr. A, 544[17], 147-184 (1991).

10) W. Suchanek, M. Yashima, M. Kakihana and M. Yoshimura, J. Am. Ceram. Soc., 80[11], 2805-2813 (1997).

11) T. Toyama, A. Oshima and T. Yasue, J. Ceram. Soc. Japan, 109[3], 232-237 (2001) [in Japanese].

12) K. Ioku, S. Yamauchi, H. Fujimori, S. Goto and $M$. Yoshimura, Solid State Ionics, 151[1-4], 147-150 (2002).

13) M. Aizawa, A. E. Porter, S. M. Best and W. Bonfield, Key Eng. Mat. Bioceramics 16, 254[2], 915-918 (2004).

14) S. Koutsopoulos, J. Biomed. Mater. Res. A, 62[4], 600-612 (2002).

15) M. Tamai, K. Sakamoto, S. Yamaguchi and A. Nakahira, $J$. Ceram. Soc. Japan, 113[2], 131-134 (2005).

16) A. Siddharthanm, S. K. Seshadri and T. S. Sampath Kumar, J. Mater. Sci. Mater. M., 15, 1279-1284 (2004).

17) L. Winand, Ann. Chim. France, 6[9-1], 941-\& (1961).

18) A. Bianco, I. Cacciotti, M. Lombardi, L. Montanaro and G. Gusmano, J. Therm. Anal. Calorim, 88[1], 237-243 (2007).

19) T. Wang, A. D. Reisel and E. Müller, J. Eur. Ceram. Soc., 24, 693-698 (2004).

20) H. F. Milhofer, V. Hlady, F. S. Baker, R. A. Beebe, N. W. Wikholm and J. S. Kittelberger, J. Colloid Interf. Sci., 70[1], 1-9 (1979).

21) A. Mortier, J. Lemaitre and P. G. Rouxhet, Thrmochim. Acta, 143[15], 265-282 (1989). 